\title{
Voice outcome indicators for unilateral vocal fold paralysis surgery: a review of the literature
}

\author{
G. Desuter ${ }^{1,3} \cdot$ M. Dedry ${ }^{1}$ B. Schaar ${ }^{1} \cdot$ J. van Lith-Bijl ${ }^{1,2} \cdot$ P. P. van Benthem ${ }^{3} \cdot$ E. V. Sjögren ${ }^{3}$
}

Received: 26 October 2017 / Accepted: 8 December 2017

(c) Springer-Verlag GmbH Germany, part of Springer Nature 2017

\begin{abstract}
Introduction There is no consensus on which voice outcome indicators (VOIs) should be used to compare the merits of the various surgical treatments for unilateral vocal fold paralysis (UVFP). Authors performed a literature review to identify which VOIs are most frequently used and most relevant, in terms of significant change in pre- and post-operative measurements, to assess UVFP surgical treatments.

Method A Medline/Pubmed literature review was performed and the most frequently used VOIs were identified using a Pareto diagram. For these most frequently used VOI's, the number of studies that showed a statistically significant change in pre- and post-operative results were compared to the total number of studies found using that same VOI, this portion was expressed in percent. This percentage was defined as the "percentage of significance" and used to assess changes of each VOI. Results Eleven VOIs were identified using the Pareto analysis. These were, in decreasing order of frequency of citation: maximum phonation time (MPT), jitter, Shimmer, video-stroboscopic examination, noise to harmonic ratio (NHR/HNR), mean air flow (MeAF), fundamental frequency (F0), "Infrequent Perceptional Scales", GRBAS scale, mean subglottic pressure (MSGP). MPT, MeAF, factor G of GRBAS-I, Jitter, shimmer and VHI-30 had respective "percentage of significance" of $90,86,85,74,68$ and $64 \%$, respectively.

Conclusion The results indicate that MPT, MeAF and GRBAS-I, represent the top-three most frequently used and the most relevant VOIs in terms of "percentage of significance". VHI-30 showed a relatively low rate of use and low "percentage of significance". The role of Jitter and Shimmer remains unclear. Finally, MSGP and the F0 appear to be less relevant VOIs for the evaluation of UFVP surgical treatments in terms of significant change in pre- and post-operative measurements.
\end{abstract}

Keywords Unilateral vocal fold paralysis UVFP · Thyroplasty · Injection laryngoplasty · Larynx reinnervation · Outcome

\section{Introduction}

Abduction in unilateral vocal fold paralysis (UFVP) causing dysphonia, dysphagia and "phonatory" dyspnea, represents a defined pathological entity for which many different surgical treatments have been proposed over the years. Although

G. Desuter

gauthier.desuter@uclouvain.be; gdesuter@post.harvard.edu

1 Otolaryngology, Head and Neck Surgery Department, Voice and Swallowing Clinic, Cliniques Universitaires Saint-Luc, Université catholique de Louvain, 10 avenue Hippocrate, suite 407, 1200 Brussels, Belgium

2 Otolaryngology Department, Flevoziekenhuis, Almere, The Netherlands

3 Otolaryngology, Head and Neck Surgery Department, LUMC, University of Leiden, Leiden, The Netherlands diverse in their approach these surgeries all primarily seek closure of the glottis during phonation. Unfortunately, there is no consensus on which voice outcome indicators (VOIs) should be used to compare the merits of these various treatments. If voice quality assessment is thought to be necessarily multidimensional, some authors have advocated, in the recent literature, the need for disease-specific sets of VOIs. This paper is a Medline/Pubmed-based review and evaluation of the literature focusing on VOIs that have been utilized for the assessment of UVFP surgical treatments.

The primary aim of this review was to determine the frequency of use of every VOI that has been utilized to assess patient's voice, after surgical treatment for UVFP, using a Pareto diagram. Having determined the most frequently used VOI's according to the Pareto diagram, the secondary aim of this review was to report their pre- and post-intervention results. The ultimate goal of the review was to identify which 
VOIs are most frequently used and most relevant in terms of significant change in pre- and post-operative measurements when it comes to assess UVFP surgical treatments.

\section{Methods}

In October 2016, a systematic search was performed in Medline/Pubmed to identify articles published after 1990 on assessment of UVFP surgical treatments. Using the following medical subject heading (MeSH) and subheadings, "Vocal Cord Paralysis/Diagnosis" [MeSH] OR "Vocal Cord Paralysis/Surgery" [MeSH] OR "Vocal CordParalysis/
Therapy" [MeSH], a total of 3052 articles were found. Two thousand two-hundred ninety-five articles (2295) were published after 1990. The first selection was based on the exclusion criteria. Seven hundred sixty articles (760) were selected after title reading. Abstracts of these 760 were reviewed. One hundred and fifty-six (156) of these articles were selected for extensive reading. Eventually, 72 of these 156 articles met the inclusions criteria and were analyzed [1-72].

Exclusion and inclusion criteria are listed in Table 1. Figure 1 shows the flowchart of article selection.

An extensive data bank was set up. Type of study, type of surgical intervention(s), type of VOI used and their values,

Table 1 Exclusion criteria are listed on the left column, Inclusion criteria are listed on the right column

\begin{tabular}{|c|c|}
\hline Exclusion criteria & Inclusion criteria \\
\hline \multicolumn{2}{|l|}{ Meta-analysis } \\
\hline Studies published before 1990 referenced in the «PubMed» database & Studies published after 1990 referenced in the « PubMed» database \\
\hline Other pathologies than unilateral vocal fold paralysis & Unilateral vocal fold paralysis \\
\hline No intervention or unspecified intervention & $\begin{array}{l}\text { Intervention (medialization thyroplasty, injection, arytenoid adduc- } \\
\text { tion, reinnervation) }\end{array}$ \\
\hline Post-surgery outcomes non available or reported in correlation & Voice outcome indicator before and after surgery \\
\hline Outcomes in dead subjects & Studies on human living subjects \\
\hline \multicolumn{2}{|l|}{ Studies about surgical complications } \\
\hline \multicolumn{2}{|l|}{ Case studies } \\
\hline Animal studies & \\
\hline
\end{tabular}

Fig. 1 Flowchart of article selection

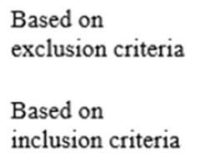

\section{2 studies}

were selected using Medical Subject Heading and Subheadings in the "PubMed » database

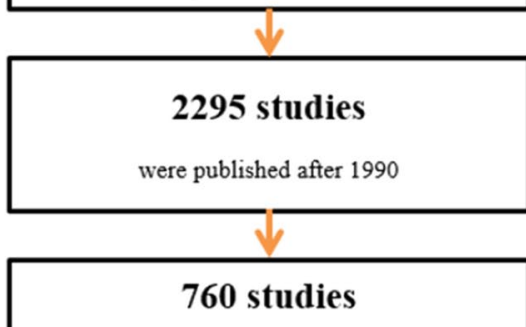

non excluded after title reading $\sqrt{3}$

\section{6 studies}

were selected for extensive reading after abstracts reviewing

\section{2 reviewed studies}

met the inclusion criteria and were analyzed
84 reviewed studies

did not meet the inclusion criteria 
Table 2 Frequency of use of the different VOIs utilized in the literature, their overall percentages of use and the cumulative percentage of all VOIs

\begin{tabular}{|c|c|c|c|}
\hline & Frequency & $\begin{array}{l}\text { Percent- } \\
\text { age }(\%)\end{array}$ & $\begin{array}{l}\text { Cumu- } \\
\text { lative } \\
\text { percent- } \\
\text { age (\%) }\end{array}$ \\
\hline MPT & 45 & 13.5 & 13.6 \\
\hline Jitter & 33 & 9.9 & 23.5 \\
\hline Shimmer & 32 & 9.6 & 33.1 \\
\hline Videostroboscopy & 30 & 9.0 & 42.2 \\
\hline NHR & 27 & 8.1 & 50.3 \\
\hline Mean air flow & 22 & 6.6 & 56.9 \\
\hline Fundamental frequency & 22 & 6.6 & 63.6 \\
\hline Homemade perceptual scales & 17 & 5.1 & 68.7 \\
\hline GRBAS-I & 16 & 4.8 & 73.5 \\
\hline Mean subglottic pressure & 10 & 3.0 & 76.5 \\
\hline VHI-30 & 9 & 2.7 & 79.2 \\
\hline Intensity & 8 & 2.4 & 81.6 \\
\hline Glottal flow rate & 6 & 1.8 & 83.4 \\
\hline NNE & 6 & 1.8 & 85.2 \\
\hline CAPE-V & 4 & 1.2 & 86.4 \\
\hline VHI-10 & 3 & 0.9 & 87.3 \\
\hline V-RQOL & 3 & 0.9 & 88.3 \\
\hline Laryngeal airway resistance & 3 & 0.9 & 89.2 \\
\hline Pitch range & 3 & 0.9 & 90.1 \\
\hline Frequency range & 3 & 0.9 & 91.0 \\
\hline Pitch perturbation quotient & 3 & 0.9 & 91.9 \\
\hline Amplitude perturbation quotient & 3 & 0.9 & 92.8 \\
\hline Phrase grouping & 2 & 0.6 & 93.4 \\
\hline Word per minute & 2 & 0.6 & 94.0 \\
\hline Maximum intensity range & 2 & 0.6 & 94.6 \\
\hline Sound pressure level & 2 & 0.6 & 95.2 \\
\hline Standard deviation of F0 & 2 & 0.6 & 95.8 \\
\hline Phonetogram & 2 & 0.6 & 96.4 \\
\hline $\begin{array}{l}\text { Vocal performance questionnaire } \\
\text { score }\end{array}$ & 1 & 0.3 & 96.7 \\
\hline NHP & 1 & 0.3 & 97.0 \\
\hline Voice symptoms scale & 1 & 0.3 & 97.3 \\
\hline Voice outcomes survey & 1 & 0.3 & 97.6 \\
\hline SR-36 & 1 & 0.3 & 97.9 \\
\hline Forced vital capacity & 1 & 0.3 & 98.2 \\
\hline Intra-abdominal pressure & 1 & 0.3 & 98.5 \\
\hline Peak expiratory flow & 1 & 0.3 & 98.8 \\
\hline Forced expiratory volume in $1 \mathrm{~s}$ & 1 & 0.3 & 99.1 \\
\hline Peak inspiratory flow & 1 & 0.3 & 99.4 \\
\hline Volume $\mathrm{O} 2$ maximum & 1 & 0.3 & 99.7 \\
\hline $\mathrm{S} / \mathrm{Z}$ ratio & 1 & 0.3 & 100.0 \\
\hline Total & 332 & 100.0 & \\
\hline
\end{tabular}

along with the time interval from the intervention date to the moment of assessment, were collected. The total frequency of use of each VOI was classified in descending order. A
Pareto diagram that combines bars showing individual values by descending order and a line graph showing the cumulative percentage of data was drawn. Using the Pareto diagram, the most frequently used VOIs, accounting for $80 \%$ of the total VOIs, were identified. Once the most frequently used VOIs had been identified, their pre- and post-intervention mean values were compared.

Two choices regarding VOI grouping were made by the authors. (a) The number of citations of noise to harmonic ratio and harmonic to noise ratio (NHR and HNR) VOIs were merged. Authors postulate that NHR and HNR represented the same VOI differing only by a software setting swopping the numerator and denominator of the same ratio. (b) Inversely, the number of citations of VHI-30 and VHI-10 was not merged. Authors postulated that they represented two different-although similar-VOIs that were based on different validation studies in different languages.

Concerning the GRBAS-I score, only the general score (G) will be considered.

The pre- and post-intervention mean values of the VOIs selected using the Pareto diagram were compared. One post-intervention VOI result was considered for each surgical technique and each time interval of post-intervention assessment. The same pre-intervention data were used in case of studies comparing (1) multiple techniques and (2) post-intervention at multiple time points. This explains why post-intervention data were more numerous than pre-intervention data.

Boxplot graphs were used to display pre- and post- intervention means. Line graphs were preferred to boxplot graphs when no clear post-operative trends in the voice outcome could be found.

Finally, for these most frequently used VOIs, the number of studies that showed a statistically significant change in pre- and post-operative results $(\leq 0.05)$ was compared to the total number of studies found using that same VOI, this portion was expressed in percent. This percentage was defined as the "percentage of significance" and used to assess changes of each VOI.

\section{Results}

Fifty-three $(73.6 \%)$ out of 72 studies were prospective. Some of these 72 studies evaluated more than one type of procedure. In total, 107 procedures were reported. Some articles did compare the outcomes of combined procedures. Surgeries of UVFP that were reported were, respectively, medialization or type 1 thyroplasty (ML) $(56.1 \%)$, arytenoid adduction (AA), usually combined with ML $(18,7 \%)$, injection laryngoplasty (IL) (17.8\%), larynx reinnervation (LR) (6.5\%) and arytenoidopexy (AP), usually combined with ML $(0.9 \%)$. 


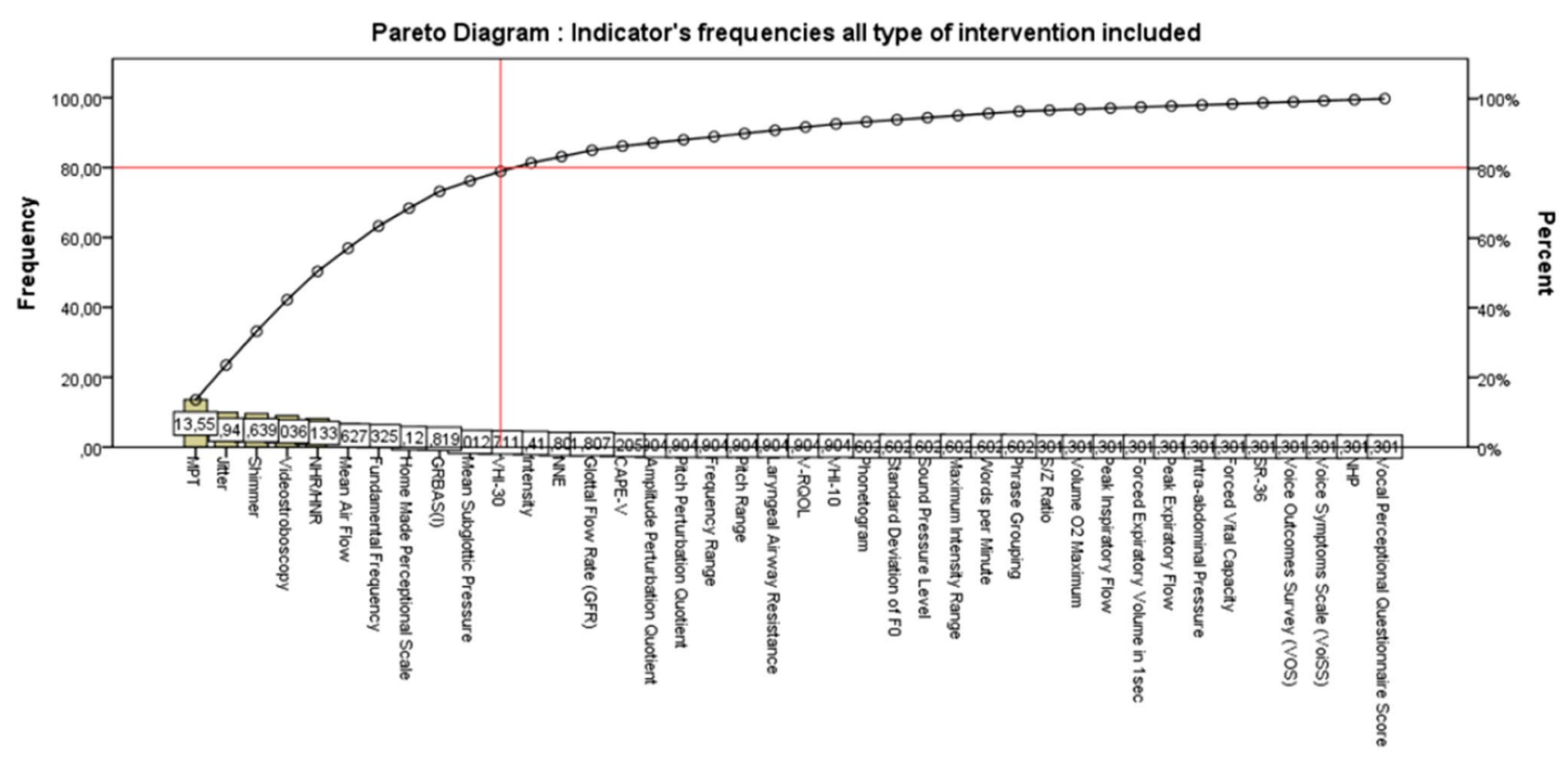

Voice outcome indicator

Fig. 2 Pareto diagram of all the VOIs that were listed

Table 3 Number of pre-op data, means of pre-intervention mean values; number of post-op data, means of post-interventions mean values, number of pre-post data delta available, for each VOI

\begin{tabular}{|c|c|c|c|c|c|c|}
\hline Voice outcome indicators & n Pré & Pré $(M, S D)$ & n Post & Post $(M, S D)$ & n Delta & Delta $(\mathrm{M}, S D)$ \\
\hline MPT (s) & 52 & $5.69(1.78)$ & 66 & $12.41(3.51)$ & 66 & $6.57(3.3)$ \\
\hline Mean airflow $(\mathrm{ml} / \mathrm{s})$ & 28 & $460(185.21)$ & 31 & $224.28(59.84)$ & 31 & 261.93(175.56) \\
\hline GRBAS-I (factor G) & 13 & $2.27(0.67)$ & 18 & $0.9(0.38)$ & 18 & $1.46(0.5)$ \\
\hline HNR (dB) & 10 & $8.8(1.83)$ & 15 & $11.6(2.08)$ & 15 & $4.1(0.9)$ \\
\hline Jitter (\%) & 35 & $5.17(3.29)$ & 46 & $1.76(0.8)$ & 46 & $3.27(2.88)$ \\
\hline Shimmer (\%) & 31 & $11.22(4.82)$ & 39 & $5.11(2.07)$ & 39 & $5.66(4.11)$ \\
\hline VHI-30 & 14 & $76.36(13.87)$ & 16 & $30.86(11.21)$ & 16 & $48.91(20.44)$ \\
\hline NHR (dB) & 15 & $0.27(0.02)$ & 20 & $0.17(0.14)$ & 20 & $0.1(0.15)$ \\
\hline Mean subglottic pressure $\left(\mathrm{cm} \mathrm{H}_{2} \mathrm{O}\right)$ & 11 & $9.58(3.93)$ & 14 & $8.8(4.5)$ & 14 & $2.77(2.63)$ \\
\hline F0 (Hz) & 24 & $172.74(38.49)$ & 36 & $166.93(28.12)$ & 36 & $25.33(26.99)$ \\
\hline
\end{tabular}

The most reported interval for post-operative voice outcome analysis was 6 months (60 articles), whereas 1 month (50 articles), 3 months (49 articles) and 1 year (48 articles) intervals were also commonly reported. Table 2 shows the details of VOI frequency of citation in descending order with their cumulative percentage. Figure 2 displays the frequency of VOIs use and the $80 \%$ cumulative percentage cut-off point within a Pareto Diagram.

Eleven VOIs accounted for $80 \%$ of all reported VOIs, when it comes to assessment of voice after surgery for UVFP. These were, in decreasing order of frequency of citation: maximum phonation time (MPT), jitter, shimmer, video-stroboscopic examination, noise to harmonic ratio (NHR/HNR), mean air flow (MeAF), fundamental frequency
(F0), "Infrequent Perceptional Scales", GRBAS scale, mean subglottic pressure (MSGP) and the original Jacobson's Voice Handicap Index (VHI-30) [73].

All the voice perceptional scales that were found in the literature whether validated, and used by only one team were grouped together in VOI "infrequent Perceptional Scales". By definition, such scales could not be compared. Likewise, video-stroboscopic examinations results could not be compared due to the lack of protocol standardization. Accordingly, the pre- and post-intervention results of the remaining nine VOIs were analyzed.

Table 3 shows means of pre-intervention values compared to means of post-interventions values for each VOI, at every given post-operative time-point. Table 4 shows the percentage 
Table 4 Proportion of studies showing significant results $(\mathrm{p} \leq 0.05)$ between pre-operative and the first post-operative assessments, for each VOI

\begin{tabular}{lll}
\hline Voice outcome indicators & $P$-values $\leq 0.05$ & $\%$ Significance \\
\hline MPT (s) & $47 / 52(0 \mathrm{NS} ; 5 \mathrm{NA})$ & 90.38 \\
Mean airflow (ml/s) & 24/28 (2 NS; 2 NA) & 85.71 \\
GRBAS-I (factor G) & $11 / 13(0 \mathrm{NS} ; 2 \mathrm{NA})$ & 84.61 \\
HNR(dB) & $8 / 10(0 \mathrm{NS} ; 2 \mathrm{NA})$ & 80 \\
Jitter (\%) & 26/35 (5 NS; 4 NA) & 74.29 \\
Shimmer (\%) & $21 / 31(6 \mathrm{NS} ; 4 \mathrm{NA})$ & 67.74 \\
VHI-30 & $9 / 14(2 \mathrm{NS} ; 3 \mathrm{NA})$ & 64.29 \\
NHR(dB) & $7 / 15(5 \mathrm{NS} ; 3 \mathrm{NA})$ & 46.67 \\
Mean subglottic pressure (cm & $5 / 11(3 \mathrm{NS} ; 3 \mathrm{NA})$ & 45.45 \\
$\quad$ H20) & & \\
F0 (Hz) & $8 / 24(6 \mathrm{NS} ; 10 \mathrm{NA})$ & 33.33 \\
\hline
\end{tabular}

The last column translates this proportion into a "percentage of significance"

$N S$ not significant, $N A$ not available

of studies showing " $P$-values $\leq 0.05$ " versus studies with " $P$-values $>0.05$ and no $P$-values available", for each VOI. For this table, only the first post-operative assessment was considered, no matter how many post-operative assessments were provided by the study. This percentage was defined as the percentage of significance.

In seven out of the nine VOIs, we found that a high percentage of the studies showed a significant difference in the pre- and post- measurements. The pre- and post-intervention means of these seven studies are displayed in Fig. 3. Figure 4 displays the pre- and post-interventions means of the remaining two VOIs, MSGP and the F0. Here no clear post-operative trends in the voice outcome could be found.

\section{Discussion}

This study is a literature review performed to reveal the most frequently cited VOIs used for UVFP surgical treatment assessment. Using the Pareto technique, eleven VOIs were found to account for $80 \%$ of the total number of indicators cited. Although the frequency of use of these VOIs may indirectly reflect their accessibility and/ or facility to measure, it does not mean per se, that these VOIs are the most appropriate or accurate for the specific purpose of UVFP surgical treatments assessment. Nevertheless, if one could propose a standardized set of VOIs, its implementation could be made easier if they are already frequently used by surgeons. Very recently, Siu et al. performed a systematic review of the literature comparing outcomes of interventions for unilateral vocal fold paralysis. They concluded that "lack of standardization in outcome measures and differences in reporting outcome data make generalizability between studies difficult" [74]. Hypothetically, an ideal standardized set of VOIs should be significant as well as accessible.

A notable effort has been made by the European Laryngological Society to standardize the description of vocal fold motion impairment as well as to propose a basic protocol for functional assessment of all voice pathologies, especially for investigating the efficacy of treatments [75, 76]. No data is available about the use of such standardizations of protocols. A survey performed in 2010 among U.S. board certified otolaryngologists conducted by Young et al., reported that only $50 \%$ of respondents performing medialization thyroplasties report collecting pre-operative voice recordings [77]. This suggests an underuse of preand post-intervention voice assessment, which is probably not only restricted to the US.

In an attempt to simplify but also make the voice assessment more accurate and significant, some authors looked at tailoring the voice assessment to the disease that is under scrutiny. Dastolfo et al. followed this strategy and demonstrated that pre- and post-operative changes in aerodynamic measurements were shown to be very significant in UVFP treatment evaluations. They specifically advocate airflow in the "all-voiced sentence" as a routine voice laboratory measure for UVFP patients [78].

Of the nine VOIs that were selected using the Pareto analysis, three VOIs have a "percentage of significance" of more than $80 \%$, Table 4. Maximum phonation time (MPT) appears to be the most used and the second most significant VOI in terms of pre- and post-operative change. Its use for UVFP treatment assessment has been frequently advocated since an initial article by Lundy et al., published in 2004, stated that "the intra-operative measure of MPT appears to be an adequate predictor of the postoperativethyroplasty- outcome" [36]. Determination of MPT is easy to perform and does not require specific equipment. There are, however, still some recording conditions and patient collaboration issues concerning the MPT. Likewise, MPT has been reported as less sensitive than MeAF to characterize laryngeal dysfunction [79].

GRBAS-I general score (G), for grade of dysphonia, represents a widely used perceptional scale. Overall voice quality is scored from 0 to 3 by listener. Inter- as well as intra-rater reliability is satisfactory [36] and there should be no obstacle to its widespread use. Nevertheless, the GRBAS-I scale has its drawbacks. It has been recently demonstrated that the GRABAS evaluation should be blind [80] and that a particular attention should be paid to task design when it comes to perceptional analysis [81].

MeAF represents a more complex VOI than the previous ones. The MeAF is a similar VOI to airflow in the "allvoiced sentence", which was shown by Dastolfo's team to be very significant in measuring the pre-post UVFP 

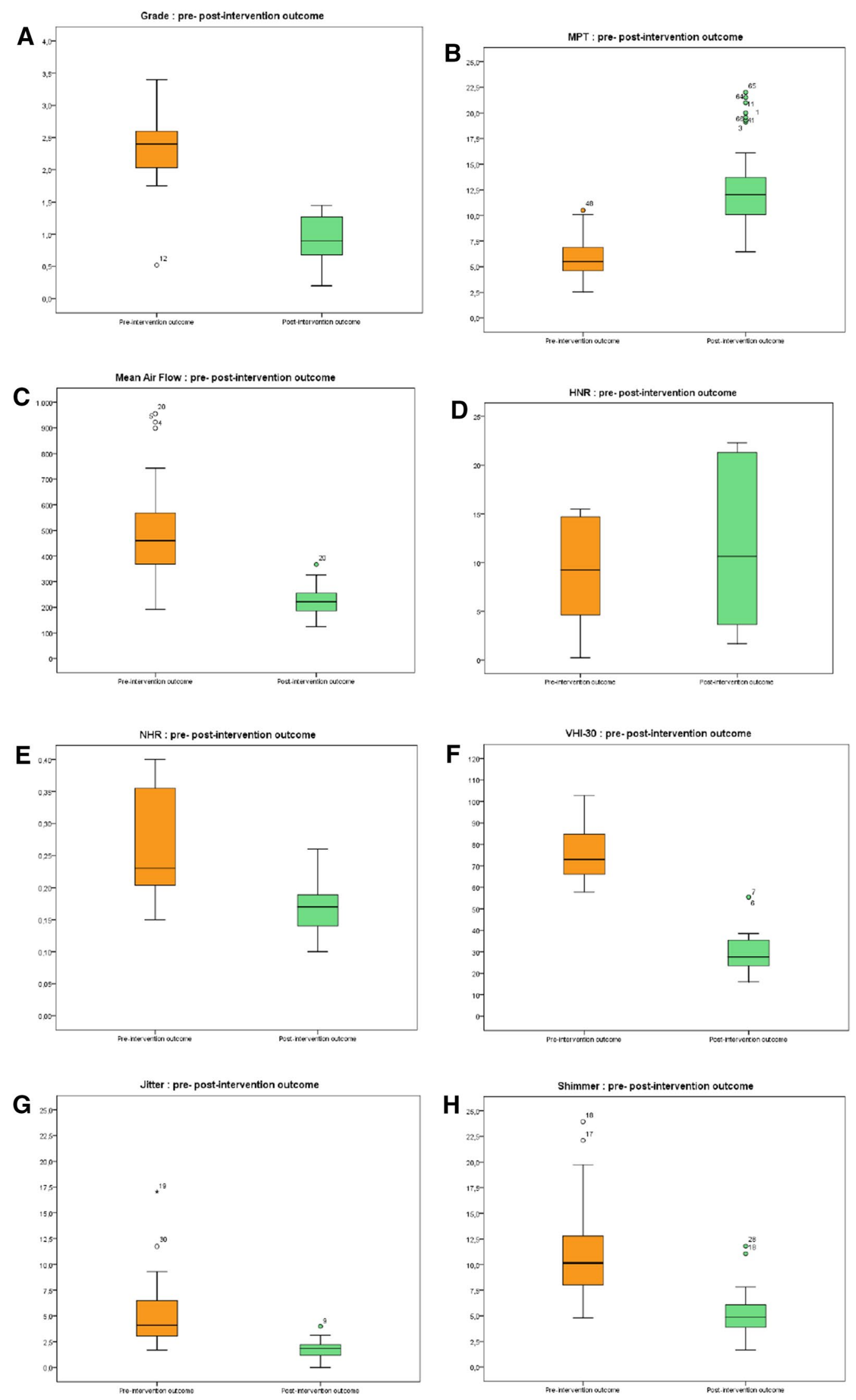

Fig. 3 Pre- and post-interventions results of G score of GRBAS-I (a), MPT (b), MeAF (c), HNR (d), NHR (e), VHI-30 (f), Jitter (g) and Shimmer (h) 


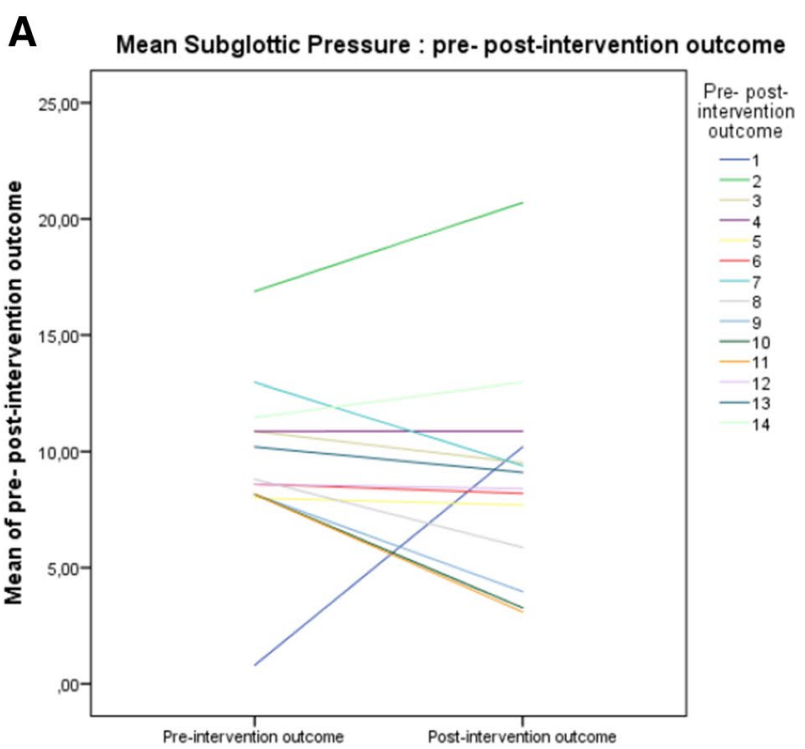

Fig. 4 Pre- and post-interventions results of MSGP (a) and F0 (b)

surgical treatment. Access to this VOI can be an issue considering the need of a pneumotachograph to be able to measure it, it is therefore somewhat reassuring to find the MeAF in our short list. Phonatory Quotient (PQ), a ratio between Vital Capacity and MPT that correlates with MeAF, could represent a valid surrogate.

Jitter and Shimmer are, respectively, ranked at fifth and sixth places in terms "percentage of significance" (Table 4). They are usually provided systematically by most voice laboratory software tools available on the market. This may explain their frequency of use, even though, their respective usefulness is questionable. As a matter of fact, Shimmer has a "percentage of significance" of only $68 \%$ and Jitter of $74 \%$. Also, Jitter is calculated with the f0, which is in itself a VOI with low significance. VHI-30 ranking is low in terms of frequency of use and significance ratio. Merging of the VHI-30 and VHI-10 would not have changed these results significantly. Mean subglottic pressure and the Fundamental Frequency do not show clear outcome tendencies after UVFP treatment, and thus, despite being widely reported, do not seem to have much added value.

The limits of this review must certainly be underscored. First, this review has been done using exclusively the Pubmed research tool. Nevertheless, we believe that the majority of the articles published on the subject, have been included although some publications might have not been considered. The sole published review on the specific topic of VOIs to assess UVFP treatments-all-together-is the recently published article by Siu et al. mentioned above.

Second, ML interventions are over-represented in comparison to IL interventions. This does not reflect the reality of practice. The main reason of this discrepancy lies in the

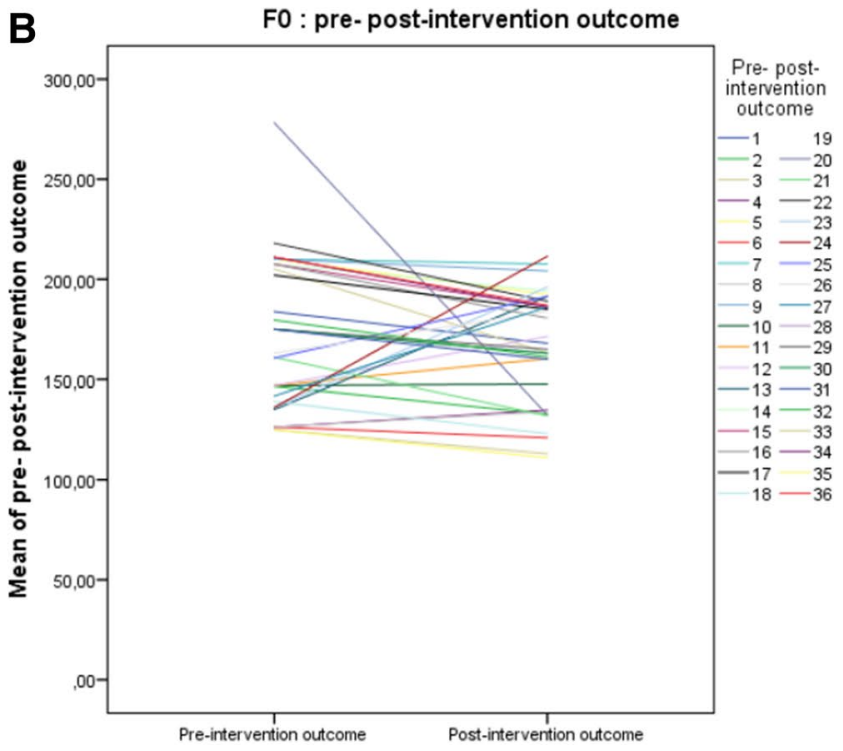

selection and inclusion criteria of the studies that favored ML interventions. Many publications concerning IL did not exclusively deal with UFVP patients and did not systematically present pre- and post-op results data.

Third, the extensive databank-more than 150 excel sheets-that has been created, may have been subject to coding errors or bias.

Fourth, raw data of these numerous studies could not be collected, limiting the validity of our conclusions. The presented outcome results are means of means. Likewise, the percentage of significance represents a ratio between studies showing statistical differences and studies showing no statistical differences or no statistical data at all. Furthermore, the fact that authors are more likely to publish significant results rather than non-significant results represents a clear bias.

Finally, this study may overlook VOIs that might be very relevant but not widely reported in the literature. Also, a statistical difference in pre- and post-operative VOI may not necessarily correspond to a clinically relevant change for the patient and the surgeon and for many VOIs there is still some uncertainty as to what the normal value and a clinically significant difference should be.

\section{Conclusion}

The goal of this review was to crossmatch frequency of use and relevance in terms of significant change in pre- and post-operative measurements of VOIs used in the evaluation of treatments of UVFP. The results indicate that MPT, MeAF and GRBAS-I represent the top-three VOIs in terms of significance within the most frequently used VOI's. The 
VHI-30 showed a relatively low rate of use and low "percentage of significance". The role of the Jitter and Shimmer remains unclear. Finally, MSGP and the F0 appear to be less relevant VOIs for the evaluation of UVFP surgical treatments in terms of significant change in pre- and postoperative measurements.

\section{Compliance with ethical standards}

Conflict of interest The authors declare that they have no conflict of interest.

Human and animal rights statement This article does not contain any studies with human or animals performed by any of the authors.

Informed consent Informed consent collection is not applicable to this study.

\section{References}

1. Abdel-Aziz MF, El-Hak NG, Carding PN (1998) Thyroplasty for functional rehabilitation of the incompetent larynx. J Laryngol Otol 112(12):1172-1175

2. Adams SG, Irish JC, Durkin LC, Wong DL, Brown DH (1996) Evaluation of vocal function in unilateral vocal fold paralysis following thyroplastic surgery. J Otolaryngol 25(3):165-170

3. Alghonaim Y, Roskies M, Kost K, Young J (2013) Evaluating the timing of injection laryngoplasty for vocal fold paralysis in an attempt to avoid future type 1 thyroplasty. J Otolaryngol Head Neck Surg 42(1):1

4. Almeida AAFD., Fernandes LR, Azevedo EHM, Pinheiro RSDA., Lopes LW (2015) Characteristics of voice and personality of patients with vocal fold immobility. CoDAS 27(2):178-185

5. Asik MB, Karasimav O, Birkent H, Merati AL, Gerek M, Yildiz Y (2015) Airway and respiration parameters improve following vocal fold medialization a prospective study. Ann Otol Rhinol Laryngol 124(12):972-977

6. Bielamowicz S, Berke GS, Gerratt BR (1995) A comparison of type I thyroplasty and arytenoid adduction. J Voice 9(4):466-472

7. Billante CR, Clary J, Childs P, Netterville JL (2002) Voice gains following thyroplasty may improve over time1. Clin Otolaryngol Allied Sci 27(2):89-94

8. Borel S, Crevier-Buchman L, Tessier C, Hans S, Laccourreye O, Brasnu D (2004) Quality of life before and after thyroplasty for vocal fold paralysis. Revue de laryngologie-otologie-rhinologie 125(5):287-290

9. Bryant NJ, Gracco LC, Sasaki CT, Vining E (1996) MRI evaluation of vocal fold paralysis before and after type I thyroplasty. Laryngoscope 106(11):1386-1392

10. Cantillo-Baños E, Jurado-Ramos A, Gutiérrez-Jódas J, ArizaVargas L (2013) Vocal fold insufficiency: medialization laryngoplasty vs calcium hydroxylapatite microspheres (Radiesse Voice $\left.{ }^{\circledR}\right)$. Acta Oto-laryngol 133(3):270-275

11. Choi HS, Chung SM, Lim JY, Kim HS (2008) Increasing the closed quotient improves voice quality after type I thyroplasty in patients with unilateral vocal cord paralysis: analysis using SPEAD program. J Voice 22(6):751-755

12. Chowdhury K, Saha S, Saha VP, Pal S, Chatterjee I (2013) Pre and post operative voice analysis after medialization thyroplasty in cases of unilateral vocal fold paralysis. Indian J Otolaryngol Head Neck Surg 65(4):354-357
13. Chhetri DK, Gerratt BR, Kreiman J, Berke GS (1999) Combined arytenoid adduction and laryngeal reinnervation in the treatment of vocal fold paralysis. Laryngoscope 109(12):1928-1936

14. Dastolfo C, Gartner-Schmidt J, Yu L, Carnes O, Gillespie AI (2015) Aerodynamic outcomes of four common voice disorders: moving toward disorder-specific assessment. J Voice 30(3):301-307

15. Desuter G, Henrard S, Boucquey D, Van Boven M, Gardiner Q, Remacle M (2015 Feb) Learning curve of medialization thyroplasty using a Montgomery ${ }^{\mathrm{TM}}$ implant. Eur Arch Otorhinolaryngol 272(2):385-390

16. Devos M, Schultz P, Guilleré F, Debry C (2010) Thyroplasty for unilateral vocal fold paralysis using an adjustable implant in porous titanium. Eur Ann Otorhinolaryngol Head Neck Dis 127(6):204-212

17. Elnashar I, El-Anwar M, Amer H, Quriba A (2015) Voice outcome after gore-tex medialization thyroplasty. Int Arch Otorhinolaryngol 19(3):248-254

18. Gliklich RE, Glovsky RM, Montgomery WM (1999) Validation of a voice outcome survey for unilateral vocal cord paralysis. Otolaryngol Head Neck Surg 120(2):153-158

19. Gray SD, Barkmeier J, Jones D, Titze I, Druker D (1992) Vocal evaluation of thyroplastic surgery in the treatment of unilateral vocal fold paralysis. Laryngoscope 102(4):415-421

20. Guerrero J, Cobeta I, García-Díaz JD, Vegas A, Montojo J, Lorenzo F, Mate A (1998) Surgery of the laryngeal framework: type I thyroplasty. Acta Otorrinolaringol Esp 49(1):45-49

21. Hajioff D, Rattenbury H, Carrie S, Carding P, Wilson J (2000) The effect of Isshiki type 1 thyroplasty on quality of life and vocal performance. Clin Otolaryngol Allied Sci 25(5):418-422

22. Harries ML, Morrison M (1995) Short-term results of laryngeal framework surgery-thyroplasty type 1: a pilot study. J Otolaryngol 24(5):281-287

23. Havas TE, Priestley KJ (2003) Autologous fat injection laryngoplasty for unilateral vocal fold paralysis. ANZ J Surg 73(11):938-943

24. Hogikyan ND, Wodchis WP, Terrell JE, Bradford CR, Esclamado RM (2000) Voice-related quality of life (V-RQOL) following type I thyroplasty for unilateral vocal fold paralysis. J Voice 14(3):378-386

25. Jang JY, Lee G, Ahn J, Son YI (2015) Early voice rehabilitation with injection laryngoplasty in patients with unilateral vocal cord palsy after thyroidectomy. Eur Arch Otorhinolaryngol 272(12):3745-3750

26. Konomi U, Watanabe Y, Komazawa D (2014) Application of pitch range evaluation subsequent to arytenoid adduction and thyroplasty. J Voice 28(3):394-395

27. Kraus DH, Orlikoff RF, Rizk SS, Rosenberg DB (1999) Arytenoid adduction as an adjunct to type I thyroplasty for unilateral vocal cord paralysis. Head neck 21(1):52-59

28. Laccourreye O, Sharkawy E, Holsinger L, Hans FC, Ménard S, M., \& Brasnu D (2005) Thyroplasty type I with montgomery implant among native French language speakers with unilateral laryngeal nerve paralysis. Laryngoscope 115(8):1411-1417

29. Leder SB, Sasaki CT (1994) Long-term changes in vocal quality following isshiki thyroplasty type I. Laryngoscope 104(3):275-277

30. Lee WT, Milstein C, Hicks D, Akst LM, Esclamado RM (2007) Results of ansa to recurrent laryngeal nerve reinnervation. Otolaryngol Head Neck Surg 136(3):450-454

31. Li AJ, Johns MM, Jackson-Menaldi C, Dailey S, Heman-Ackah Y, Merati A, Rubin AD (2011) Glottic closure patterns: type I thyroplasty versus type I thyroplasty with arytenoid adduction. J Voice 25(3):259-264

32. Lorenz RR, Esclamado RM, Teker AM, Strome M, Scharpf J, Hicks D, \& Lee WT (2008) Ansa cervicalis-to-recurrent laryngeal 
nerve anastomosis for unilateral vocal fold paralysis: experience of a single institution. Ann Otol Rhinol Laryngol 117(1):40-45

33. Lu FL, Casiano RR, Lundy DS, Xue JW (1996) Longitudinal evaluation of vocal function after thyroplasty type I in the treatment of unilateral vocal paralysis. Laryngoscope 106(5):573-577

34. Lu FL, Lundy DS, Casiano RR, Xue JW (1998) Vocal evaluation of thyroplasty type I in the treatment of nonparalytic glottic incompetence. Ann Otol Rhinol Laryngol 107(2):113-119

35. Lundy DS, Casiano RR, Mc Clinton ME, \& Xue JW (2003) Early results of transcutaneous injection laryngoplasty with micronized acellular dermis versus type-I thyroplasty for glottic incompetence dysphonia due to unilateral vocal fold paralysis. J Voice 17(4):589-595

36. Lundy DS, Casiano RR, Xue JW (2004) Can maximum phonation time predict voice outcome after thyroplasty type I? Laryngoscope 114(8):1447-1454

37. Lundy DS, Casiano RR, Xue JW, Lu FL (2000) Thyroplasty type I: short- versus long-term results. Otolaryngol Head Neck Surg 122(4):533-536

38. Mahieu H, Norbart TH, Snel F (1996) Laryngeal framework surgery for voice improvement. Revue de laryngologie-otologierhinologie 117(3):189-197

39. Malik A, Ramalingam WVBS., Nilakantan A, Nair S, Ramesh AV, Raj P (2014) Comparison of the use of silastic with titanium prefabricated implant in type I thyroplasty. Braz J Otorhinolaryngol 80(2):156-160

40. Manfredi C, Peretti G (2006) A new insight into postsurgical objective voice quality evaluation: application to thyroplastic medialization. IEEE Trans Biomed Eng 53(3):442-451

41. Matar N, Remacle M, Bachy V, Lawson G, Giovanni A, LejolyDevuyst V, Legou T (2012) Objective measurement of real time subglottic pressure during medialization thyroplasty: a feasibility study. Eur Arch Otorhinolaryngol 269(4):1171-1175

42. McLean-Muse A, Montgomery WW, Bunting G, Hillman RE, Doyle P, Varvares M, Eng J (2000) Montgomery ${ }^{\circledR}$ thyroplasty implant for vocal fold immobility: phonatory outcomes. Ann Otol Rhinol Laryngol 109(4):393-400

43. Mohammed H, Masterson L, Gendy S, Nassif R (2016) Outpatient based injection laryngoplasty for the management of unilateral vocal fold paralysis-clinical outcomes from a UK centre. Clin Otolaryngol 41(4):341-346

44. Morgan JE, Zraick RI, Griffin AW, Bowen TL, Johnson FL (2007) Injection versus medialization laryngoplasty for the treatment of unilateral vocal fold paralysis. Laryngoscope 117(11):2068-2074

45. Mortensen M, Carroll L, Woo P (2009) Arytenoid adduction with medialization laryngoplasty versus injection or medialization laryngoplasty: the role of the arytenoidopexy. Laryngoscope 119(4):827-831

46. Murata T, Yasuoka Y, Shimada T, Shino M, Iida H, Takahashi K, Furuya N (2011) A new and less invasive procedure for arytenoid adduction surgery. Laryngoscope 121(6):1274-1280

47. Nouwen J, Hans S, De Mones E, Brasnu D, Crevier-Buchman L, Laccourreye O (2004) Thyroplasty type I without arytenoid adduction in patients with unilateral laryngeal nerve paralysis: the Montgomery implant versus the Gore-Tex implant. Acta otolaryngol 124(6):732-738

48. Omori K, Slavit DH, Kacker A, Blaugrund SM (1996) Quantitative criteria for predicting thyroplasty type I outcome. Laryngoscope 106(6):689-693

49. Paniello RC, Edgar JD, Kallogjeri D, Piccirillo JF (2011) Medialization versus reinnervation for unilateral vocal fold paralysis: a multicenter randomized clinical trial. Laryngoscope 121(10):2172-2179

50. Parker NP, Barbu AM, Hillman RE, Zeitels SM, Burnas JA (2015) Revision transcervical medialization laryngoplasty for unilateral vocal fold paralysis. Otolaryngol Head Neck Surg 153(4):593-598

51. Peretti G, Provenzano L, Piazza G, Giudice M, Antonelli AR (2001). Risultati funzionali dopo tiroplastica di I tipo con protesi di Montgomery. Acta Otorhinolaryngol Ital, 21, 156-161

52. Prendes BL, Yung KC, Likhterov I, Schneider SL, Al-Jurf SA, Courey MS (2012) Long-term effects of injection laryngoplasty with a temporary agent on voice quality and vocal fold position. Laryngoscope 122(10):2227-2233

53. Ryu IS, Nam SY, Han MW, Choi SH, Kim SY, Roh JL (2012) Long-term voice outcomes after thyroplasty for unilateral vocal fold paralysis. Arch Otolaryngol Head Neck Surg 138(4):347-351

54. Sakai N, Nishizawa N, Matsushima JI, Kurihara H, Kokubun T, Koichi KI, ... \& Inuyama Y (1996) Thyroplasty type I with ceramic shim. Artif Organs 20(8):951-954

55. Sasaki CT, Leder SB, Petcu L, Friedman CD (1990). Longitudinal voice quality changes following Isshiki thyroplasty type I: the Yale experience. Laryngoscope 100(8), 849-852

56. Schwarz K, Cielo CA, Steffen N, Becker J, Jotz GP (2011) Voice and laryngeal configuration of men with unilateral vocal fold paralysis before and after medialization. J Voice 25(5):611-618

57. Shin JE, Nam SY, Yoo SJ, Kim SY (2002) Analysis of voice and quantitative measurement of glottal gap after thyroplasty type I in the treatment of unilateral vocal paralysis. J Voice 16(1):136-142

58. Smith ME, Houtz DR (2016) Outcomes of laryngeal reinnervation for unilateral vocal fold paralysis in children: associations with age and time since injury. Ann Otol Rhinol Laryngol 125(5):433-438

59. Sonoda S, Kataoka H, Inoue T (2005) Traction of lateral cricoarytenoid muscle for unilateral vocal fold paralysis: comparison with Isshiki's original technique of arytenoid adduction. Ann Otol Rhinol Laryngol 114(2):132-138

60. Sridhara SR, Ashok KG, Raghunathan M, Mann SBS (2003) To study voice quality before and after thyroplasty type 1 in patients with symptomatic unilateral vocal cord paralysis. Am J Otolaryngol 24(6):361-365

61. Stuut M, Gi RETP., Dikkers FG (2014) Change of voice handicap index after treatment of benign laryngeal disorders. Eur Arch Otorhinolaryngol 271(5):1157-1162

62. Suehiro A, Hirano S, Kishimoto Y, Tanaka S, Ford CN (2009). Comparative study of vocal outcomes with silicone versus GoreTex thyroplasty. Ann Otol Rhinol Laryngol 118(6):405-408

63. Thompson DM, Maragos NE, Edwards BW (1995) The study of vocal fold vibratory patterns in patients with unilateral vocal fold paralysis before and after type I thyroplasty with or without arytenoid adduction. Laryngoscope 105(5):481-486

64. Tokashiki R, Hiramatsu H, Shinada E, Motohashi R, Nomoto M, Toyomura F, Suzuki M (2012) Analysis of pitch range after arytenoid adduction by fenestration approach combined with type I thyroplasty for unilateral vocal fold paralysis. J Voice 26(6):792-796

65. Tokashiki R, Hiramatsu H, Tsukahara K, Kanebayashi H, Nakamura M, Motohashi R, Yamada T, Suzuki M (2007) A "fenestration approach" for arytenoid adduction through the thyroid ala combined with type I thyroplasty. Laryngoscope 117(10):1882-1887

66. Tucker HM (1999) Long-term preservation of voice improvement following surgical medialization and reinnervation for unilateral vocal fold paralysis. J Voice 13(2):251-256

67. Umeno H, Chitose S, Sato K, Nakashima T (2009) Comparative study of framework surgery and fat injection laryngoplasty. J Laryngol Otol 123(S31):35-41

68. Umeno H, Chitose SI, Sato K, Nakashima T (2008) Efficacy of additional injection laryngoplasty after framework surgery. Ann Otol Rhinol Laryngol 117(1):5-10

69. Umeno H, Chitose SI, Sato K, Ueda Y, Nakashima T (2012) Long-term postoperative vocal function after thyroplasty type 
I and fat injection laryngoplasty. Ann Otol Rhinol Laryngol 121(3):185-191

70. Vinson KN, Zraick RI, Ragland FJ (2010). Injection versus medialization laryngoplasty for the treatment of unilateral vocal fold paralysis. Laryngoscope 120(9):1802-1807.

71. Wen MH, Cheng PW, Liao LJ, Chou HW, Wang CT (2013) Treatment outcomes of injection laryngoplasty using cross-linked porcine collagen and hyaluronic acid. Otolaryngol Head Neck Surg. https://doi.org/10.1177/0194599813508082.

72. Zur KB, Carroll LM (2015) Recurrent laryngeal nerve reinnervation in children: acoustic and endoscopic characteristics preintervention and post-intervention. A comparison of treatment options. Laryngoscope 125(S11):S1-S15

73. Jacobson BH, Johnson A, Silbergeit GrywalskiC, Jocobson A, Benninger G, Newman MS; C.W (1997))The voice handicap index (VHI): development and validation. Am J Speech Lang Pathol 6:66-70

74. Siu J, Tam S, Fung K (2016) A comparison of outcomes in interventions for unilateral vocal fold paralysis: a systematic review. Laryngoscope 126(7):1616-1624

75. Dejonckere PH, Bradley P, Clemente P, Cornut G, Crevier-Buchman L, FriedrichG, Van De Heyning P, Remacle M, Woisard V; Committee on Phoniatrics of the European Laryngological Society (ELS) (2001) A basic protocol for functional assessment of voice pathology, especially for investigating the efficacy of (phonosurgical) treatments and evaluating new assessment techniques. Guideline elaborated by the Committee on Phoniatrics of the European Laryngological Society (ELS). Eur Arch Otorhinolaryngol 258(2):77-82

76. Rosen CA, Mau T, Remacle M, Hess M, Eckel HE, Young VN, Hantzakos A, Yung KC, Dikkers FG (2016) Nomenclature proposal to describe vocal fold motion impairment. Eur Arch Otorhinolaryngol 273(8):1995-1999

77. Young VN, Zullo TG, Rosen CA (2010) Analysis of laryngeal framework surgery: 10-year follow-up to a national survey. Laryngoscope 120(8):1602-1608

78. Dastolfo C, Gartner-Schmidt J, Yu L, Carnes O, Gillespie AI (2016) Aerodynamic outcomes of four common voice disorders: moving toward disorder-specific assessment. J Voice 30(3):301-307

79. Woo P, Casper J, Colton R, Brewer D (1994) Aerodynamic and stroboscopic findings before and after microlaryngeal surgery. $\mathrm{J}$ Voice 8(2):186-194

80. Webb AL, Carding PN, Deary IJ, MacKenzie K, Steen N, Wilson JA (2004) The reliability of three perceptual evaluation scales for dysphonia. Eur Arch Otorhinolaryngol 261(8):429-434

81. Ghio A, Revis J, Merienne S, Giovanni A (2013) Top-down mechanisms in dysphonia perception: the need for blind tests. J Voice 27(4):481-485 